\title{
Review Article \\ Determination of Microalgal Lipid Content and Fatty Acid for Biofuel Production
}

\author{
Zhipeng Chen, Lingfeng Wang, Shuang Qiu $\mathbb{D}$, and Shijian Ge \\ Jiangsu Key Laboratory of Chemical Pollution Control and Resources Reuse, School of Environmental and Biological Engineering, \\ Nanjing University of Science and Technology, Xiao Ling Wei 200, Nanjing, Jiangsu 210094, China
}

Correspondence should be addressed to Shuang Qiu; qiushuang89@njust.edu.cn and Shijian Ge; geshijian1221@njust.edu.cn

Received 29 December 2017; Revised 12 March 2018; Accepted 4 April 2018; Published 21 May 2018

Academic Editor: Xiaoling Miao

Copyright (C) 2018 Zhipeng Chen et al. This is an open access article distributed under the Creative Commons Attribution License, which permits unrestricted use, distribution, and reproduction in any medium, provided the original work is properly cited.

\begin{abstract}
Biofuels produced from microalgal biomass have received growing worldwide recognition as promising alternatives to conventional petroleum-derived fuels. Among the processes involved, the downstream refinement process for the extraction of lipids from biomass greatly influences the sustainability and efficiency of the entire biofuel system. This review summarizes and compares the current techniques for the extraction and measurement of microalgal lipids, including the gravimetric methods using organic solvents, $\mathrm{CO}_{2}$-based solvents, ionic liquids and switchable solvents, Nile red lipid visualization method, sulfo-phospho-vanillin method, and the thin-layer chromatography method. Each method has its own competitive advantages and disadvantages. For example, the organic solvents-based gravimetric method is mostly used and frequently employed as a reference standard to validate other methods, but it requires large amounts of samples and is time-consuming and expensive to recover solvents also with low selectivity towards desired products. The pretreatment approaches which aimed to disrupt cells and support subsequent lipid extraction through bead beating, microwave, ultrasonication, chemical methods, and enzymatic disruption are also introduced. Moreover, the principles and procedures for the production and quantification of fatty acids are finally described in detail, involving the preparation of fatty acid methyl esters and their quantification and composition analysis by gas chromatography.
\end{abstract}

\section{Introduction}

Nowadays, limited stock of petroleum-derived fuel resources combined with perpetually increasing demands for energy due to the rapid industrialization and population growth has troubled many governments and organizations across the world [1]. Moreover, the combustion of fossil-derived fuels has led to increasing emission of greenhouse gases such as carbon dioxide $\left(\mathrm{CO}_{2}\right)$, leading to global climate change and posing threats to the biosphere [2]. In order to achieve sustainable development, the critical issues noted above and the gradually rising fossil-derived fuel prices have called for the needs to search for alternative sustainable and renewable energy sources [3].

Biofuels, produced from biomass, are promising alternatives to fossil-derived fuels due to several distinct advantages including carbon neutrality, reduced emissions of gaseous pollutants (e.g., carbon monoxide, $\mathrm{CO}_{2}$, and sulfur oxides), continuous availability of biomass feedstocks, and their safety of production by farming [4]. According to their physical characteristics, biofuels are divided into solid (i.e., biochar), liquid (i.e., bioethanol, vegetable oil, and biodiesel), and gaseous (i.e., biogas, biosyngas, and biohydrogen) fuels. Based on the types of used feedstocks, biofuels are categorized into three generations. The first generation feedstocks mainly include food crops such as corn, soybean, rapeseed, sunflower, and palm oil. The second-generation biofuels are derived from nonedible feedstocks like Jatropha, Miscanthus, Switch grass, and other organic wastes. Nevertheless, the expanding demand for edible feedstocks as food sources and their need for large areas of arable land for production have limited the development of both the first- and second-generation biofuels. The use of microalgae as a thirdgeneration biofuel feedstock avoids these issues and presents several distinct advantages of not requiring agricultural or arable lands for production, high photosynthetic efficiencies and biomass productivities (biomass doubled in less than one day), and 100 times more lipids per acre of land $[5,6]$. 

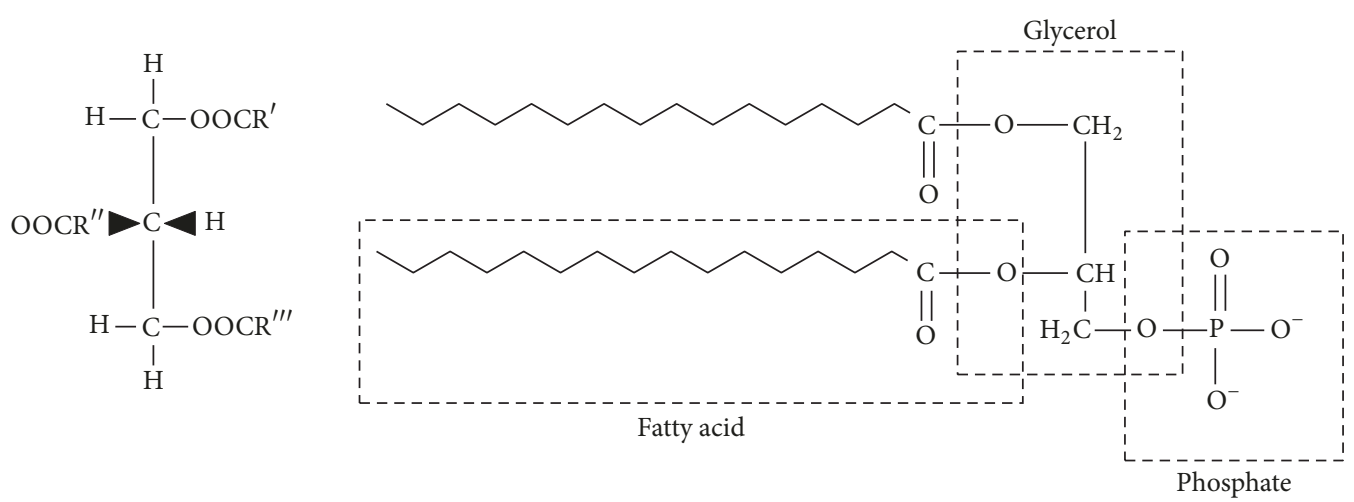

FIgure 1: Lipid molecules. Triacylglycerol (NL) on the left. Phospholipid (polar lipid) on the right. $\mathrm{R}^{\prime}, \mathrm{R}^{\prime \prime}$, and $\mathrm{R}^{\prime \prime \prime}$ in the triacylglycerol molecule represent fatty acid chains. Phospholipid molecule is negatively charged [15].

Moreover, the main storage lipids in microalgae are neutral lipids (NLs) or triacylglycerols that can be esterified to FAMEs with the primary profiles of $\mathrm{C} 16$ and $\mathrm{C} 18$, proven to be the most suitable for biofuel production [7]. Microalgae exhibit great adaption to various environmental conditions, making them easy to cultivate. For instance, they can grow on marginal land in both the open pond and closed systems using waste streams like wastewater, waste or $\mathrm{CO}_{2}$-enriched gas (biogas, flue gas), waste organics (i.e., crude glycerol), and waste heat to provide nutrients and carbon and temperature maintenance (in a cold climate), achieving economically feasible and environmentally sustainable biofuel production and waste bioremediation [8]. Moreover, various routes of microalgal metabolisms can be adopted for enhanced growth and lipid production. Traditionally, phototrophic algae are grown autotrophically with $\mathrm{CO}_{2}$ as the unique carbon source and light providing all the energy needed. Moreover, some microalgae species can grow heterotrophically using only organic compounds, while others can grow mixotrophically using both organic compounds and $\mathrm{CO}_{2}$ to support growth [9].

Currently, the high costs of the important microalgal harvesting and lipid extraction processes are the primary obstacles impeding on the commercial application of microalgaederived biofuel production [10-12]. For example, lipid extraction is a high-power-consumption process because lipids are stored in microalgal cells and the cell wall is a thick and rigid layer composed of complex carbohydrates and glycoproteins with high mechanical strength and chemical resistance, posing difficulties for lipid extraction [13]. Therefore, certain cell disruption techniques are generally considered prior to lipid extraction to improve the extraction efficiencies. Nevertheless, the efficiencies of cell disruption and lipid extraction vary with methods selected with different operating conditions (e.g., temperature, atmospheric pressure, and humidity), microalgae species, and biomass amount.

This review summarizes and compares the methodologies employed for the extraction and quantification of microalgal lipids. The pretreatment methods supporting cell disruption and subsequent lipid extraction are also included. Finally, the principles and procedures for the production and quantification of fatty acids in microalgae are discussed in detail.

\section{Microalgal Lipids}

Microalgal lipids can be divided into two groups according to their structures: nonpolar NLs (acylglycerols, sterols, free fatty acids, wax, and steryl esters) and polar lipids (phosphoglycerides, glycosylglycerides, and sphingolipids). Figure 1 shows the structural formula of the polar lipid and NLs $[14,15]$. These lipids play different but important roles in microalgal metabolism and growth period. Some lipids such as phosphoglycerides, glycosylglycerides, and sterols are imperative structural components of biological membranes, while lipids like inositol lipids, sphingolipids, and oxidative products of polyunsaturated fatty acids may act as key intermediates in the cell signaling pathways and play a role in sensing changes in the environment [16]. The quantities of these microalgal lipids vary with the type of species, growth conditions, and ambient environments. It was reported that the lipid contents ranged at $20-50 \%$ of dry biomass including Chlorella, Crypthecodinium, Cylindrotheca, Dunaliella, Isochrysis, Nannochloris, Nannochloropsis, Neochloris, Nitzschia, Phaeodactylum, Porphyridium, Schizochytrium, and Tetraselmis [17].

\section{Microalgal Cell Disruption Methods}

Specific microalgal cell pretreatment procedures must be considered prior to the subsequent lipid extraction due to the microalgal cell wall structure. When the extraction is conducted from the wet biomass, the pretreatment step is mandatory to disrupt the microalgal cell walls and allow the lipids to be released into the extracting mixture. The commonly used pretreatment methods are summarized below.

3.1. Bead Beating. Bead beating, also known as bead mill or ball mill, disrupts cells by the impact of high-speed spinning of fine beads on the biomass slurry. The whole disruption process could be done within minutes, and it could be applied to any kinds of microalgae without preparation [18, 19]. Two common types of bead mills are shaking vessels and agitated beads [20]. Shaking vessels usually consist of multiple containers or well-plates on a vibrating platform, and the cell disruption is done by shaking the entire vessel 
on a vibrating platform. The shaking vessels are usually employed in laboratory, as they are only suitable for multiple samples requiring similar disruption treatment conditions. Comparatively, the agitated beads type that is made up of a rotating agitator in a fixed vessel filled with beads and cell culture could achieve better disruption efficiencies. However, the cooling jackets must be equipped to protect the heat-sensitive biomolecules as the rotating agitator generates heat during disruption process $[18,19]$. The combination of agitation, collision, and grinding of the beads could produce a higher disruption efficiency [20]. To sum up, the simplicity of the equipment and the rapidness of the treatment process are the two main advantages of bead beating methods, while the requirement of an extensive cooling system to protect the target products has limited it to scale up [18].

3.2. Microwave. Microwave is an electromagnetic wave with the frequency ranging between $300 \mathrm{MHz}$ and $300 \mathrm{GHz}$, which is lower than that of infrared and higher than that of radio waves. Microwave-assisted extraction technology has been studied for extracting target compounds in a few fields, including microalgal lipid extraction [50]. When microalgal cells are exposed to the microwave with the specific frequency (approximately $2450 \mathrm{MHz}$ ), cell molecules generate a rapid oscillation within the rapidly oscillating electric field, resulting in the heat generation due to the frictional forces from the inter- and intramolecular movements [51]. The intracellular heating causes the water to vapor, which disrupts the cells and subsequently opens up the cell membrane. This method exhibits strong advantages of short reaction time, lowoperating costs, and efficient extraction with all of the species, but the requirement of a vast cooling system to protect target products limits its large-scale application $[18,19]$.

3.3. Ultrasonication. Ultrasonication has been a well-known method for the microbial cell disruption due to its short reaction time with high productivity [52]. When the ultrasound is applied to the liquid cultures, small "vacant regions" called microbubbles are momentarily formed as the liquid molecules are moved by the acoustic waves. Meanwhile, the production of microbubbles causes cavitation, which in turn creates pressure on the cells to break up [53]. During the treatment, the rapid compression/decompression cycles of the sonic waves generate transient and stable cavitation. The transient cavitation occurs when oscillations that cavitation undergoes are unsteady and implode ultimately. This type of implosion could produce extremely localized shock waves and high temperature, the conditions of which impart mechanical stress on the cells and crack the cell wall and membrane [54]. On the other hand, the cavitation that oscillates for many cycles is referred to as stable cavitation, which can produce microscale eddies, inducing stress or physiological changes in microorganisms [55]. Ultrasonic horn and bath are the two basic types of sonicators, and they are commonly employed in batch operations but can also be adapted for continuous operations [56]. Horns use piezoelectric generators, which are made of lead zirconate titanate crystals and vibrate with amplitude of $10-15 \mathrm{~mm}$. As the energy generated at the horn tip dissipates rapidly with distance, the cavitation must be created with sufficient disruptive force. Transducers placed at the bottom of the sonicator are used in sonicator baths to generate ultrasonic waves. In sonicator baths, the number and arrangement of transducers vary according to the capacity and shape of the sonicator [20]. The working conditions of ultrasonication treatment are easy to set up and the whole process could be done in a very short time while with high reproducibility [19]. However, it is difficult to scale up as cavitation, the strong effect of which is able to achieve cell disruption only occurs in small regions near ultrasonic probes.

3.4. Chemical Method. The rupture of cells occurs when chemicals are used to increase the permeability of cell up to a particular value [57]. It was reported that, through chemical treatments with acids (i.e., $\mathrm{HCl}$ and $\mathrm{H}_{2} \mathrm{SO}_{4}$ ), alkalis (i.e., $\mathrm{NaOH}$ ), and surfactants, chemical linkages on the microalgal cell envelope were degraded followed by the lysis of cell wall [58]. Comparatively, chemical treatment consumes less energy because it does not require a large amount of heat or electricity while showing higher efficiency of cell disruption. However, the continuous consumption of chemicals challenges the economic sustainability of this method. Moreover, acids and alkalis have a high risk of corroding the reactor and attacking microalgal lipids, thus ruining the whole process [18].

3.5. Enzymatic Disruption. In addition to the autolysis, the use of foreign lytic enzymes is extensively investigated because enzymes are the commercially available and easily controlled biological materials [59]. Specific enzyme is able to degrade certain structural cell components, thus improving the release of desired intracellular compounds [60]. In some cases, a mixture of different enzymes is reported to have a better economic and technical feasibility, and the lipid yields could be improved when enzymatic hydrolysis is combined with acid/alkaline pretreatment. Compared to the chemical method that possibly destroys every particle existing in the solution and even induces side-reactions of the target products (i.e., lipids), the reaction condition of enzymatic method is mild, and its selectivity is high with specific chemical linkages. Moreover, enzymatic disruption combined with other methods is usually considered for economic process and improved disruption performance [18]. However, more researches need to be conducted to reduce the high cost and relatively long treatment time, which have limited the largescale application of this method.

3.6. Other Methods. Apart from the methods noted above, there are some other microalgal cell disruption approaches that have been investigated as well. For example, when the mixture of microalgae and other solvents is sprayed through a narrow tube under high pressure, hydraulic shear force is generated and high pressure homogenization (HPH), also known as French press, makes use of this force to extract internal substances of microalgae. By measuring the increase in the soluble chemical oxygen demand (SCOD) during the cell disruption, lots of researchers have evaluated the cell disruption efficiency and found that HPH exhibited high cell 


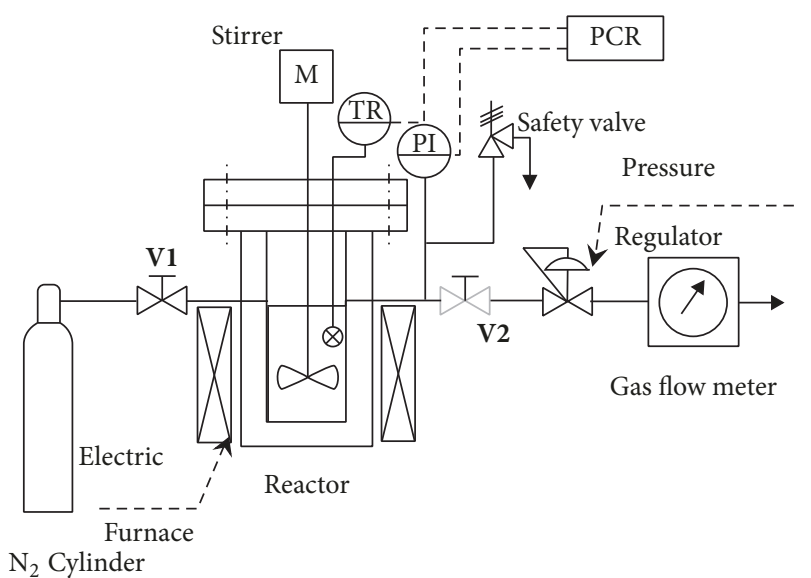

FIGURE 2: Schematic diagram of thermal pretreatment apparatus [61].

disruption efficiency. It is worth mentioning that $\mathrm{HPH}$ has lots of advantages such as producing less heat during the extraction process, thus requiring less cooling cost and it is easy to scale up. However, the pretreatment process relying on $\mathrm{HPH}$ requires a relatively long time and consumes quite a few amount of power. Electroporation can achieve permanent cell disruption by applying a much stronger electromagnetic field (EF) to the biomass that can damage the cell envelopes beyond their healing abilities since the application of an EF of suitable intensity will lead to the formation of pores on the cell envelopes of the cells, and the pores are closed by a healing process when the EF is removed. Electroporation is a promising cell disruption method as it requires simple equipment and operation procedures with high energy efficiency $[18,20]$. Thermal treatment could achieve effective recovery of hydrocarbons as well and a typical process of thermal pretreatment is shown in Figure 2. Firstly, place the samples in vessel and replace the air in the vessel by nitrogen gas. Then, heat vessel to the set temperature, and afterwards, cool the vessel to the ambient temperature after maintaining the samples at the set temperature. Then, stir the samples mechanically. Finally, open the autoclave and carefully remove the samples for further analysis [61]. Recently, plenty of work have been done to compare the efficiency of different cell disruption methods; however, due to the different species of microalgae used in experiments so as the different operating temperatures, atmospheric pressures, and other influence factors, the efficiency of different cell disruption methods is short of comparability.

\section{Microalgal Lipid Extraction and Quantification Approach}

The microalgal lipid extraction refers to the process of separating the valuable NLs and fatty acids from the cellular matrix and water. As far, multiple methods have been reported for the quantification of microalgal lipids, mainly including the conventional gravimetric method using extraction solvents, Nile red lipid visualization method, SPV, and TLC [62-64].

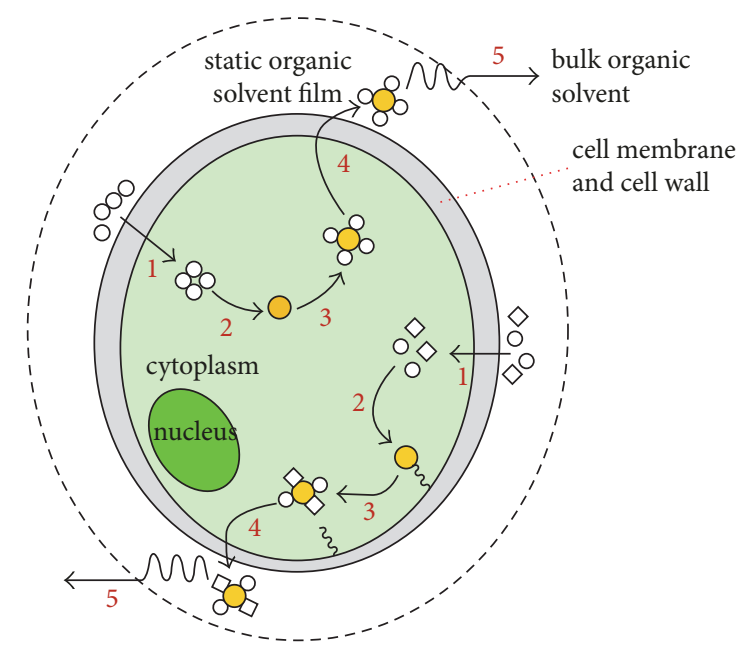

FIGURE 3: Schematic diagram of the organic solvent-based microalgal lipid extraction mechanisms. The pathway shown at the top of the cell is for nonpolar organic solvent while the pathway shown at the bottom of the cell is for nonpolar/polar organic solvent mixture. Orange circle: lipids, white circle: nonpolar organic solvent, and white diamond: polar organic solvent [15].

4.1. Gravimetric Method. The gravimetric method is most widely used to determine microalgal lipid content. It is also frequently used as a reference standard to validate other methods. The gravimetric method consists of the lipid extraction using solvents and lipid quantification achieved by recording the weight of extracted lipids after evaporating the extracting solvents. The extraction solvents used include the conventional organic solvents, $\mathrm{CO}_{2}$-based solvents, ionic liquids (ILs), and switchable solvent.

4.1.1. Organic Solvent Extraction. The chemistry concept of "like dissolving like" is the basic principle underlying the organic solvent-based extraction of microalgal lipids. Figure 3 illustrates the principle of the 5-step-microalgae lipid extraction mechanism. Typically, the organic solvents penetrate through the cell membrane into the cytoplasm (step 1) and interact with the lipid complex (step 2). During this process, the nonpolar organic solvent interacts with NLs through van der Waals associations, while the polar organic solvent interacts with the polar lipids by generating hydrogen bonds that are strong enough to replace the lipidprotein associations that prevent nonpolar organic solvent from accessing the lipids. Subsequently, an organic solventlipids complex is produced (step 3), followed by the organic solvent-lipids complex diffusing across the cell membrane (step 4) and the static organic solvent film (step 5) into the bulk organic solvent driven by a concentration gradient.

The commonly used organic solvent extraction procedures are summarized in Table 1. The nonpolar organic solvents, such as hexane, benzene, toluene, diethyl ether, ethyl acetate, and chloroform, are usually combined with the polar organic solvents to maximize the extraction efficiency of NLs. As such, when lipid extraction is achieved with the use of a nonpolar/polar organic solvent mixture, the 


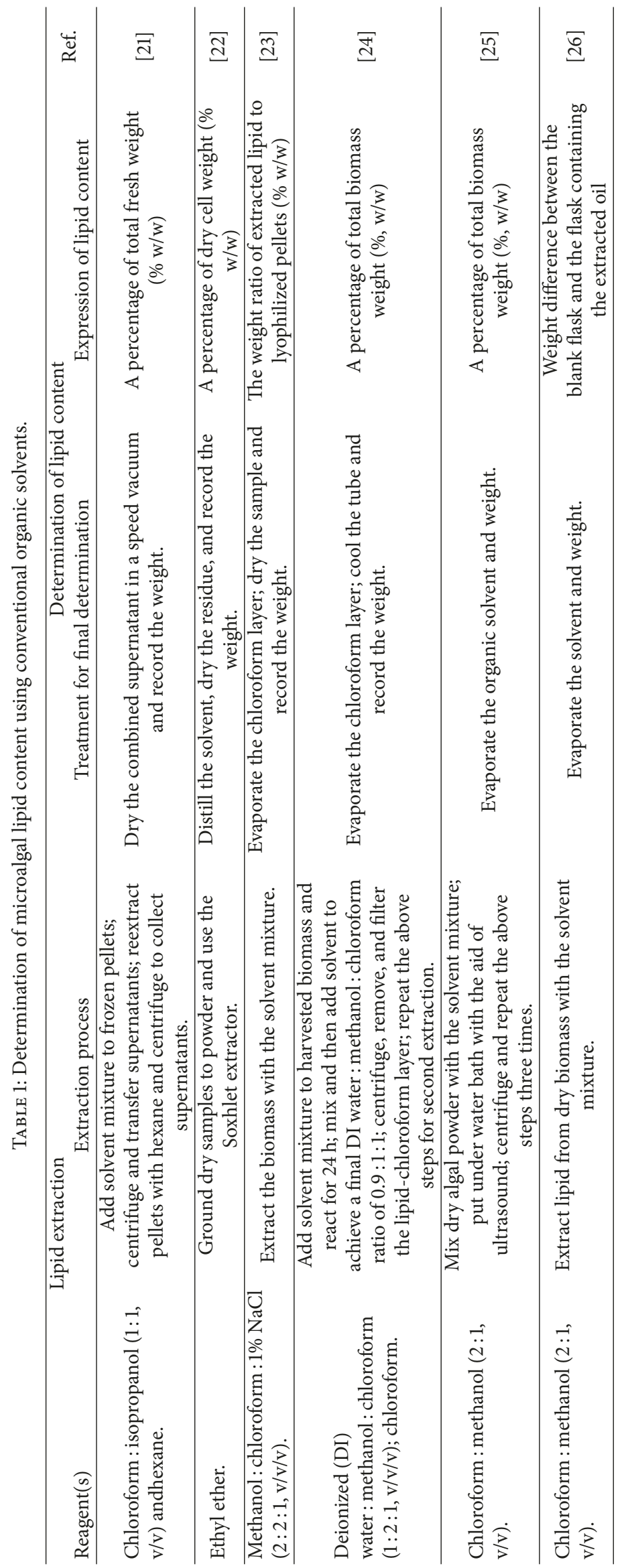


TABLE 2: Comparisons between conventional organic solvents extraction and $\mathrm{CO}_{2}$-based solvents extraction approaches.

\begin{tabular}{lccc}
\hline Items & Organic solvent & $\mathrm{scCO}_{2}$ & $\mathrm{LO}_{2}$ \\
\hline $\begin{array}{l}\text { Heavy metal contamination } \\
\text { Inorganic salt content }\end{array}$ & Unavoidable & Free of heavy metals & Free of heavy metals \\
$\begin{array}{l}\text { Selectivity } \\
\text { Extracted compounds }\end{array}$ & Poor selectivity & Free of inorganic salts & Free of inorganic salts \\
Safety & Polar and nonpolar compounds & Honphly selective & Highly selective \\
Operation condition & Flammable and/or toxic & Nontoxic and nonflammable & Nontoxic and nonflammable \\
Recycling & Regular temperature and pressure & High temperature and pressure & Lower temperature and pressure \\
Operation cost & Solvent recovery is expensive & $\mathrm{CO}_{2}$ could be recycled and reused & $\mathrm{CO}_{2}$ could be recycled and reused \\
Extraction time & High power consumption (in & High power consumption & Lower than scCO \\
\hline
\end{tabular}

polar organic solvent is intended to disrupt the neutralpolar lipid complexes while the nonpolar organic solvent aims to solubilize the intracellular NLs [65]. Moreover, the lipid yields vary with the type of used organic solvents and the ratios of polar solvents to nonpolar solvents. Therefore, the final lipid extraction efficiencies using different organic solvents extraction methods cannot be impartially compared. In addition, the different experiment steps, equipment, and experimental conditions involved in the extraction process also contribute to various extraction results.

The organic solvent-based extraction methods usually require a relatively large quantity of biomass and have few environmental impacts. In addition, organic solvents are not highly selective towards the desired neutral (mono-, di-, and triacylglycerols) lipids and free fatty acid components; some of them are not easily removable, posing difficulties to the subsequent process. An ideal solvent for the lipid extraction should be free of toxicity, easy to remove, and more selective towards target products. These characteristics have been found in $\mathrm{CO}_{2}$-based solvents, ionic liquids, and switchable solvents, which will be introduced hereinafter.

4.1.2. $\mathrm{CO}_{2}$-Based Solvent Extraction. The supercritical $\left(\mathrm{scCO}_{2}\right)$ and liquid $\left(\mathrm{CCO}_{2}\right) \mathrm{CO}_{2}$ are able to solubilize many organic molecules and can be easily recycled at the end of the process while leaving no residual solvents, making them promising alternatives to traditional organic solvents.

(1) $s c \mathrm{CO}_{2}$ Extraction. The supercritical fluid extraction (SFE) is a promising green technology that can potentially displace the use of traditional lipid extraction procedure, due to its high selectivity, short extraction time, and their absent use of toxic organic solvents [66]. As can be seen from Table 2, $\mathrm{scCO}_{2}$ has been regarded with interest in the field of SFEs, because it offers advantages of negligible environmental impact, high diffusivity, no toxicity, no oxidation or thermal degradation of extracts, and easy separation of desired bioproducts [67]. Moreover, $\mathrm{scCO}_{2}$ has high selectivity towards microalgal NLs (mono-, di-, and triacylglycerols) and has been used in the lipid extraction of microalgae such as Cylindrotheca closterium, Arthrospira maxima, Nannochloropsis oculate, Chlorella vulgaris, and Spirulina platensis [68-71].
For example, Halim et al. [72] employed $\mathrm{scCO}_{2}$ into a wet Chlorococum sp. paste to obtain a yield of $7.1 \mathrm{wt} \%$ at a temperature of $333 \mathrm{~K}$ and a pressure of $30 \mathrm{MPa}$ over an $80 \mathrm{~min}$ extraction time. Moreover, coupling the nonpolar $\mathrm{scCO}_{2}$ with the polar cosolvents (i.e., methanol, ethanol, and toluene) could enhance the affinity towards NLs that form complexes with polar lipids, resulting in a greater biofuel production [73]. The general procedure of $\mathrm{scCO}_{2}$ extraction is described as follows: $\mathrm{CO}_{2}$ is first condensed to $\mathrm{CCO}_{2}$ and then to the $\mathrm{scCO}_{2}$. Subsequently, the fluid is pumped into the extraction vessel under the desired and controlled conditions of pressure and temperature. After the extraction, the extracted lipids are precipitated and collected into a glass trap, cooled in an ice bath with the amount assessed by gravimetry. It should be noted that the effects of operating conditions (i.e., extraction vessel size and type, pressure, and extraction time) involved in the $\mathrm{scCO}_{2}$ extraction process noted above on the lipid yield and selectivity should be investigated on a case-by-case basis. Moreover, the high temperature (i.e., $100^{\circ} \mathrm{C}$ ) and pressure (i.e., $41 \mathrm{MPa}$ ) requirement are the main concerns that have limited this approach from industrial-scale application [74].

(2) $l \mathrm{CO}_{2}$ Extraction. Comparatively, $\mathrm{lCO}_{2}$ shares many of the same benefits as $\mathrm{scCO}_{2}$ while it requires lower temperature and pressure than $\mathrm{scCO}_{2}$ extraction (Table 2) and therefore has emerged as a possible substitute. Paudel et al. [75] recovered about $26 \mathrm{wt} \%$ of the extractable lipids using $1 \mathrm{CO}_{2}$ directly from the wet biomass of Chlorella vulgaris under different pressures $(6.8-17 \mathrm{MPa})$ and a constant temperature of $25^{\circ} \mathrm{C}$. An extraction example using $\mathrm{lCO}_{2}$ is described as follows. Firstly, $\mathrm{ICO}_{2}$ is pressurized to a certain pressure (i.e., $6.8 \mathrm{MPa}$ ) using the high pressure pump and during this process, a coolant (i.e., 75\% ethyleneglycol in distilled water) must be used to keep the pump at $-5^{\circ} \mathrm{C}$ to prevent it from being heated. Secondly, the pressurized $\mathrm{CCO}_{2}$ is delivered through the tube coil to tube vessel, aiming to make $\mathrm{CO}_{2}$ coming from the cold pump warm up to the temperature of the water bath. Thirdly, the vessel containing dry algae is heated in water bath at $25^{\circ} \mathrm{C}$ for $2 \mathrm{~h}$, during which the required pressure in the system is maintained by backpressure regulator (BPR). After the extraction, the remaining $\mathrm{CO}_{2}$ is vented into the flask, and the remaining extract exiting the 


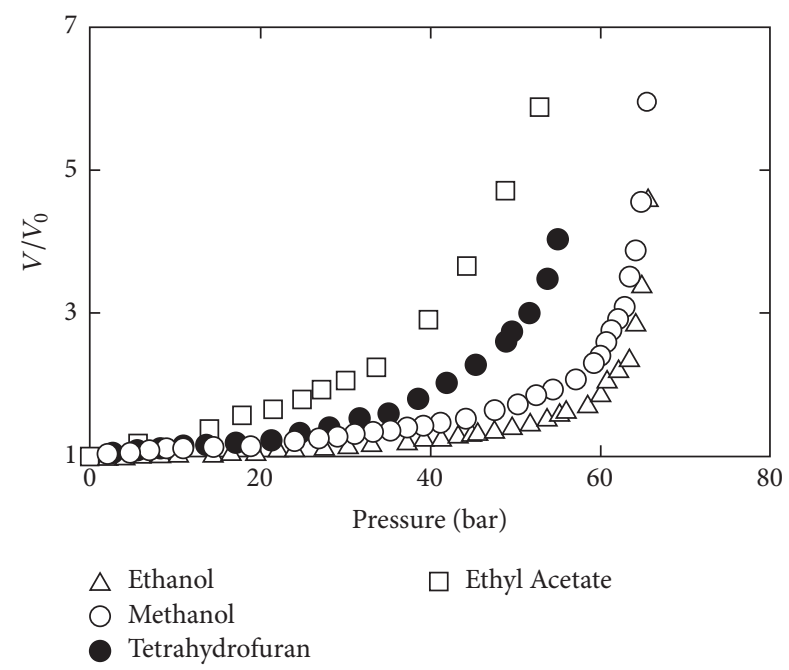

FIGURE 4: Isothermal volumetric expansion of benign solvents by $\mathrm{CO}_{2}$ at $40^{\circ} \mathrm{C}[77]$.

BPR is captured, separated, and dried. The extract is then preserved in the ice-cold isopropanol.

(3) Gas Expanded Liquids Extraction. Gas expanded liquids (GXLs) are liquids expanded in volume by the application of modest pressures with a compressible gas, among which $\mathrm{CO}_{2}$ is one of the most commonly used gases [76]. The GXLs are made up of a mixture of compressed gases and conventional solvents. Jessop and Subramaniam [77] reported that GXL solvents have the combined beneficial properties of a compressed gas and organic solvent, so the properties of solvent can be adjusted through variations in the pressure. As can be seen from Figure 4, the gaseous $\mathrm{CO}_{2}$ has a considerable solubility in many benign organic solvents at adequate pressures $(<8 \mathrm{MPa})$ such as ethanol, methanol that show a 2 - to 3 -fold volumetric expansion at relatively mild pressures and moderate temperatures [77]. As such, various principles and applications of $\mathrm{CO}_{2}$-expanded liquids (CXLs) including lipid extraction have been proposed [78, 79]. Due to the fact that CXLs can be operated at mild temperatures and pressures, a reduction in process costs and energy consumption could be realized. The mass transfer rates can also be improved via CXLs by reducing interfacial tension and viscosity as well as increasing diffusivity [80]. Wang et al. [78] used the $\mathrm{CO}_{2}$-expanded ethanol to successfully extract lipids from Schizochytrium sp. with a $35.7 \mathrm{wt} \%$ lipid content of dry biomass. The $\mathrm{CO}_{2}$-expanded methanol increased up to $82 \%$ of the selectivity of methanol towards the extraction of biodiesel-desirable NLs and free fatty acids [75].

4.1.3. ILs Extraction. ILs are organic salts with the melting point below $100^{\circ} \mathrm{C}$, and they typically consist of large asymmetric organic cations coupled with smaller anions [81]. Advantages such as thermal stability, synthetic flexibility, nonvolatility, nonflammability, recyclability, and unique solvent properties have made ILs promising replacements of traditional organic solvents in lipid extraction as they can dissolve highly recalcitrant biopolymers [82]. For instance, ILs are capable of disrupting cell structure in wet microalgae biomass under mild conditions. This allows either autopartitioning of the lipids or presumably improving access of cosolvents to the intracellular lipids, thus facilitating the extraction of lipids from microalgae and making it faster than organic solvent extraction processes. Most solventbased extraction processes, however, are incompatible with wet biomass, which add significant costs to the overall process since dewatering and drying processes are thought to be responsible for up to $70 \%$ of the biofuel production cost [83].

A typical lipid extraction procedure with the aid of ILs is described as follows [84]. Firstly, mix microalgae paste with $1: 10$ mass ratio of dry equivalent microalgae to $\left[\mathrm{C}_{2} \mathrm{mim}\right]$ $\left[\mathrm{EtSO}_{4}\right]$ and incubate the mixture. Secondly, add water to the mixture to improve separation after the addition of hexane and remove the top layer to a new container. The procedures noted above are repeated three times to achieve a high extraction efficiency. After the extraction, wash the extracts with $\mathrm{NaCl}$ and transfer the target part to a preweighed vessel. The mass of extractable lipids is measured after evaporating the solvent. For ILs recycling, add methanol/water to the mixture to precipitate the residual solids and pool hexane with the previous extraction. Subsequently, filter the solvent and wash with methanol/methanol to collect ILs, and then ILs are recovered by evaporation.

4.1.4. Switchable Solvents Extraction. Switchable solvents, known as "reversible" or "smart" solvents, can reversibly change their properties upon addition or removal of a "trigger." The switchable solvents (subclass of ILs) are divided into two categories, switchable polarity solvents (SPSs) and switchable hydrophilicity solvents (SHSs) [85, 86]. Specifically, the polarity of SPSs exhibits variation with the solution $\mathrm{CO}_{2}$ concentration. The polarity of the solvents can be reversed by removing the $\mathrm{CO}_{2}$ from the system by heating or sparging the solution with nonacidic gases. SPSs are divided into two classes, which are either single-component or twocomponent species. In the two-component SPSs, a base with an alcohol or with an amine is usually included while singlecomponent SPSs require a primary or secondary amine [85]. Unlike SPSs, SHSs can change from a hydrophobic solvent into a hydrophilic one, and their potential applications have extended to the extraction of microalgal lipids [87]. In the SHSs system, the hydrophobic form creates a biphasic mixture with water, and the hydrophilic form is the corresponding bicarbonate salt; thus SHSs could also be reversibly converted between the above two forms by the addition or removal of $\mathrm{CO}_{2}[88,89]$. A proposed lipid extraction procedure using SHSs is illustrated in Figure 5. Briefly, SHSs are employed to dissolve or extract lipids in their hydrophobic state; the carbonated water is introduced to revert SHSs's hydrophilic form and form a two-phase of the lipid and SHSs/water; finally, the SHSs/water mixture would be separated into two components and then be reused by flushing air through [88].

4.2. Nile Red Lipid Visualization Method. Compared with the mostly used gravimetric methods noted above, Nile 


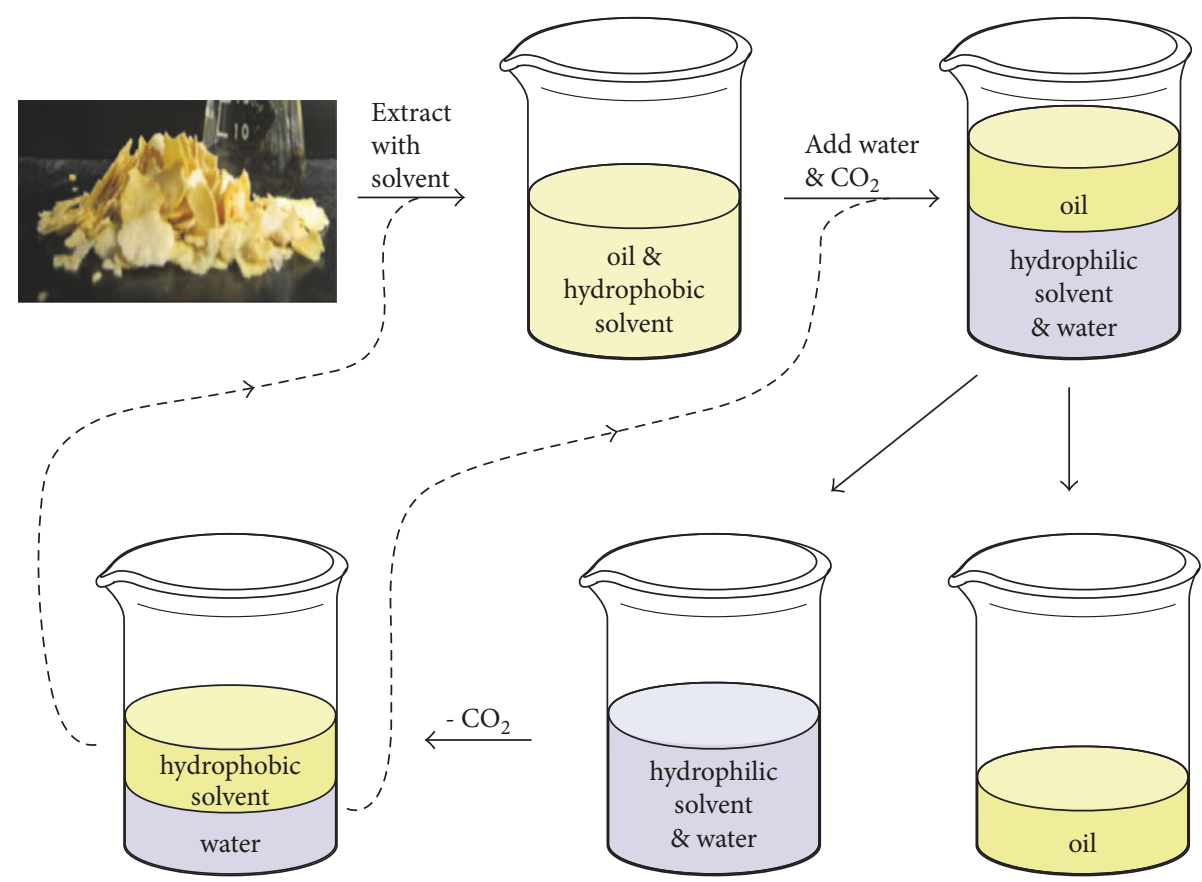

FIGURE 5: The process of SHSs used for soybean oil extraction from soybean flakes without a distillation step. The dashed lines indicate the recycling of the solvent and the aqueous phase [88].

red lipid visualization method is more convenient as the number of samples and preparation time are greatly reduced. The Nile red (9-diethylamino-5H-benzo[ $\alpha$ ]phenoxazine-5one) is a lipid-soluble probe that fluoresces at the defined wavelengths depending upon the polarity of the surrounding medium. However, due to the composition and structure of the thick and rigid cell walls in some microalgae species, Nile red is prevented from penetrating the cell wall and cytoplasmic membrane, and therefore, lipids cannot provide the desired fluorescence. Thus, the dimethyl sulfoxide (DMSO) is introduced to microalgal samples as the stain carrier at an elevated temperature [63]. When microalgal lipids are measured by Nile red visualization method, a standard curve preparation is included in most cases. Table 3 summarizes some specific Nile red lipid procedures for the determination of microalgal lipids. Different solvents are combined with Nile red solution to stain microalgal culture samples, and the samples are diluted if necessary. The lipid content determination is achieved by comparing the resulting fluorescence values to a certain standard curve, in which the wavelength of excitation and emission may be different. Nevertheless, the lipid contents measured by this method are usually interfered by the environmental factors and other components in the cell cytoplasm, and the fluorescence intensity varies between samples. Thus, the optimal spectra and reaction conditions should be determined for each type of sample prior to the fluorescent measurement [90].

4.3. SPV Method. The colorimetric SPV method is a rapid alternative for lipid measurement because of its fast response and relative ease in sample handling [91]. The SPV reacts with lipids to produce a distinct pink color, and the intensity is quantified using spectrophotometric methods; therefore, it is employed for direct quantitative measurement of lipids within liquid microalgal cultures [40]. However, the results of SPV assay can be affected by lots of factors such as the degree of oil saturation, incubation time, heating, and cooling; thus the SPV assay may give misleading results [27].

The general procedure of SPV method includes the sample addition, solvent evaporation, sulfuric acid addition, samples incubation, color developing by adding phosphovanillin reagent, absorbance reading, and measurement of the lipid content based on the standard curve [62]. Phosphovanillin reagent is prepared by dissolving vanillin in absolute ethanol and DI water, followed by the addition of concentrated $\mathrm{H}_{3} \mathrm{PO}_{4}$. To prepare standard lipid stocks, canola oil is firstly added to chloroform, and then different amount of standard lipid stocks is added to the tubes. After that, these tubes are treated to evaporate the solvent followed by the addition of water. Subsequently, these samples are prepared by following SPV reaction methods: (1) suspend tested samples in water and place in a glass tube; (2) add concentrated sulfuric acid followed by heat treatment and ice bath; (3) add freshly prepared phosphovanillin reagent and incubate in incubator shaker; (4) read absorbance at $530 \mathrm{~nm}$ and determine the lipid content by comparing to the standard curve.

4.4. TLC Method. TLC is also a promising alternative to conventional lipids measurement approaches as it requires minimal equipment which is available in most laboratories, and it can also provide additional information about lipid classes, which is important for biofuel production [92]. Among different solvent systems, the multi-one-dimensional TLC (MOD-TLC) separates the lipid classes rapidly and 


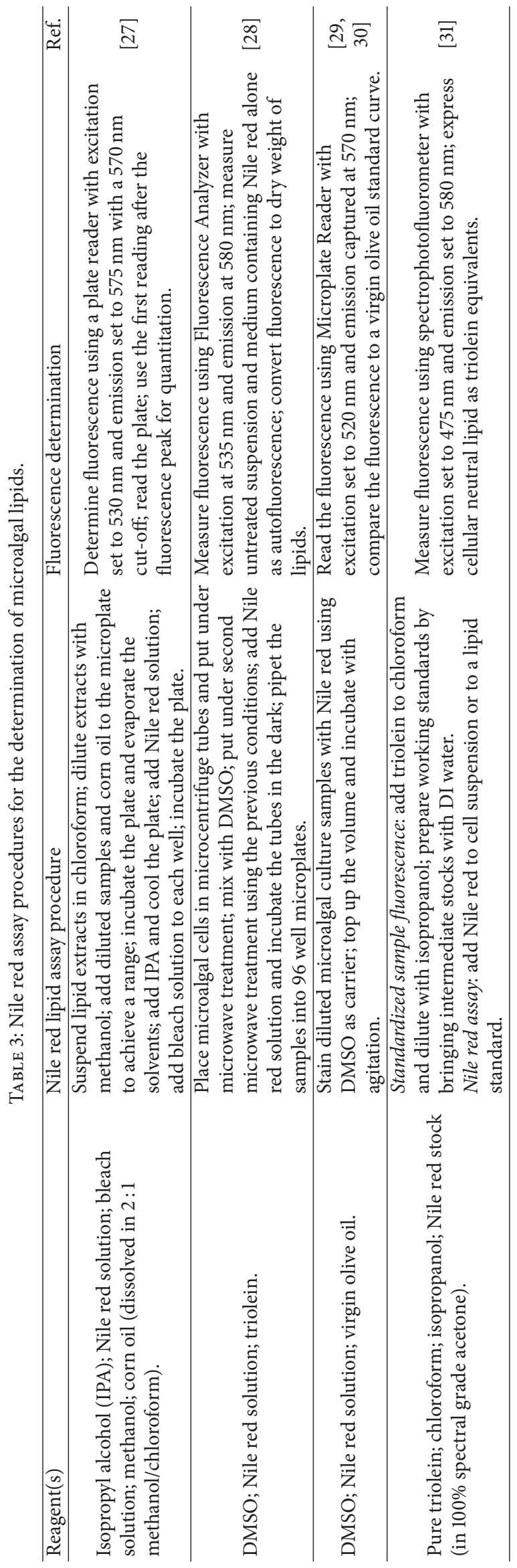


reproducibly. The MOD-TLC method can achieve the quantification for the majority of microalgal lipids through modifications in solvent mixtures and lengths of separation times, and the mass of each resolved lipid band is determined by comparing band intensities of unknown samples (visualized by the lipophilic dye primulin followed by an automated laser-fluorescence detector scanning) to dilution curves of authentic standards. Compared to two-dimensional thinlayer chromatography, MOD-TLC directly analyzes multiple samples on a single TLC plate, while still providing good resolution for the quantification of most major classes of lipid species [32]. Some TLC running procedures are introduced in detail (Table 4). Usually, TLC plates must be activated before TLC running, and NLs are separated by certain solvents such as a mixture of chloroform: methanol:acetic acid: water $(85: 12.5: 12.5: 3, \mathrm{v} / \mathrm{v} / \mathrm{v} / \mathrm{v})$. The determination of microalgal lipid content is finally achieved by comparing the resulting fluorescence values with a standard curve.

\section{Quantification for Microalgal Fatty Acids}

The theoretical biofuel potentials of microalgal biomass are ultimately determined by the acyl chains of the lipids, and therefore the lipid contents are quantified as the sum of their fatty acid constituents. The fatty acids constituents vary with their structural features such as chain length, degree of saturation, branching of carbon chain, positional isomers, configuration of double bonds, or other chemical groups (i.e., hydroxy, epoxy, cyclo, and keto) [93]. It was reported that $\mathrm{C} 16$ and $\mathrm{C} 18$ are the most abundant microalgal fatty acids including palmitic acid (hexadecanoic, C16:0), stearic acid (octadecanoic, C18:0), oleic acid (octadecenoic, C18:1), linoleic acid (octadecadienoic, C18:2), and linolenic acid (octadecatrienoic, C18:3). The other fatty acids such as C14, C20, and C26-C32 are relatively in low concentrations [94].

Table 5 summarizes and compares different methods of the measurement and quantification of microalgal fatty acids. These methods consisted of two steps: (1) the preparation of FAMEs; (2) quantification and composition analysis of FAMEs by gas chromatography (GC). In the first step via the transesterification or in situ transesterification process, the triglycerides contained in algal lipids are reacted with methanol to produce FAMEs and glycerol. Catalysts (acid catalyst, base catalyst, or the mixture) and heat (water or oil bath) are usually required during the transesterification process to speed up the reaction. The common catalysts for this transesterification include $\mathrm{NaOH}$ [95], $\mathrm{HCl}$ [35], $\mathrm{H}_{2} \mathrm{SO}_{4}$ [37], acetyl chloride/methanol $(1: 10, \mathrm{v} / \mathrm{v})$ [42], and a mixture of methanol, $\mathrm{H}_{2} \mathrm{SO}_{4}$, and chloroform $(1.7: 0.3: 2.0, \mathrm{v} / \mathrm{v} / \mathrm{v})$ [47]. In the second step, the separation of FAMEs from the mixture and their quantification are performed using GC. The procedure noted above is based on the amount of fatty acids after the lipid extraction in algal biomass. Comparatively, the in situ transesterification is a relatively simpler process and achieves the transesterification to get FAMEs directly from the whole biomass with no requirement of lipid extraction. Therefore, it is able to obtain all fatty acids in the biomass and accurately represent the reflection of biofuels potential $[49,96]$. In addition, various procedures for transesterification are followed in terms of microalgal species, lipid contents, and targeted FAMEs fraction. The specific transesterification procedures performed in literature are listed in Table 5. In brief, the lipid extracts or the algal biomass are mixed with the catalysts and methanol and are reacted at the conditions of high temperature. The produced FAMEs are then recovered in solvents like hexane for further purification and quantification. Subsequently, the purified FAMEs are separated and analyzed by GC equipped with the flame ionization detector (FID) and specific columns running at various temperatures. The identification and quantification standards are required such as the commercial 37-component standards, pentadecanoic acid, and heptadecanoic acid [40, 41, 47, 48, 97]. Specific FAMEs are quantified by comparing their peak areas with those of the standards. It should be noted that there is still not a routine method for the quantification of fatty acids specific to algal biomass issued by Association of Analytical Communities (AOAC) International. All the methods noted above vary significantly including the procedures, types of used chemicals and their doses, and analytical apparatus. This might result in a lack of comparability between FAMEs concentrations obtained from different methods.

\section{Conclusion}

Microalgae have proven to be one of the most promising feedstocks for the production of third-generation biofuels that are both economically feasible and environmentally sustainable. Rapid, accurate, sustainable, and cost-effective methods for the lipid extraction and quantification are essential for the rational application of microalgae-based biofuel production. Gravimetric method is most widely used but requires quite a few amount of samples; Nile red lipid visualization method is rapid as the number of samples and preparation time are greatly reduced while a correlation between fluorescence and lipid levels must be previously established as the cell staining varies among different microalgae species; the results of SPV assay can be affected by lots of factors such as the degree of oil saturation, incubation time, heating, and cooling; thus the SPV assay may give misleading results; in addition to the quantitative measurement of microalgal lipids, TLC can also provide additional information about lipid classes which is important for biofuel production. Various lipid quantification methods could be considered on a case-by-case basis, but more effective and greener techniques (e.g., $\mathrm{CO}_{2}$-based methods) for microalgal cell disruption and extraction are still required to maximize lipid yields while avoiding the issues of toxicity, flammability, and time consumption for extraction. In addition, the identification and quantification of fatty acids in extracted lipids are also important to evaluate the quality of microalgae-derived biofuel, during which transesterification and in situ transesterification are involved in the preparation of FAMEs for the further the quantification and composition analysis of FAMEs by GC. It is worth mentioning that in situ transesterification is relatively simpler and more convenient as it does not require lipid extraction, thus achieving the transesterification to get FAMEs directly from the whole biomass. 


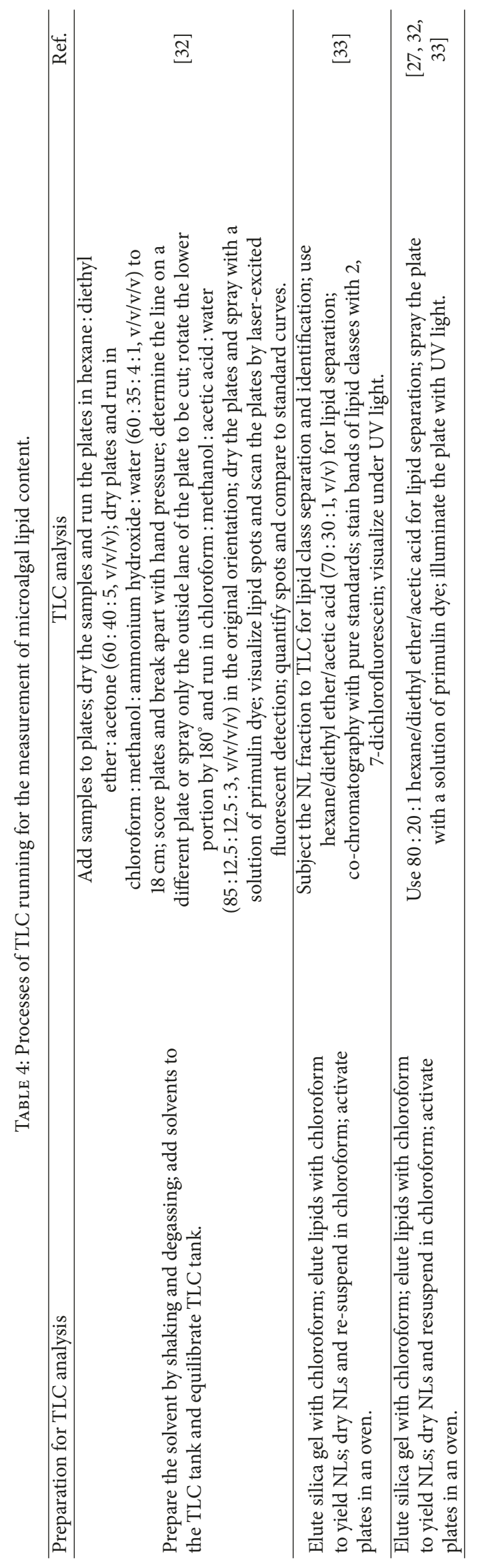




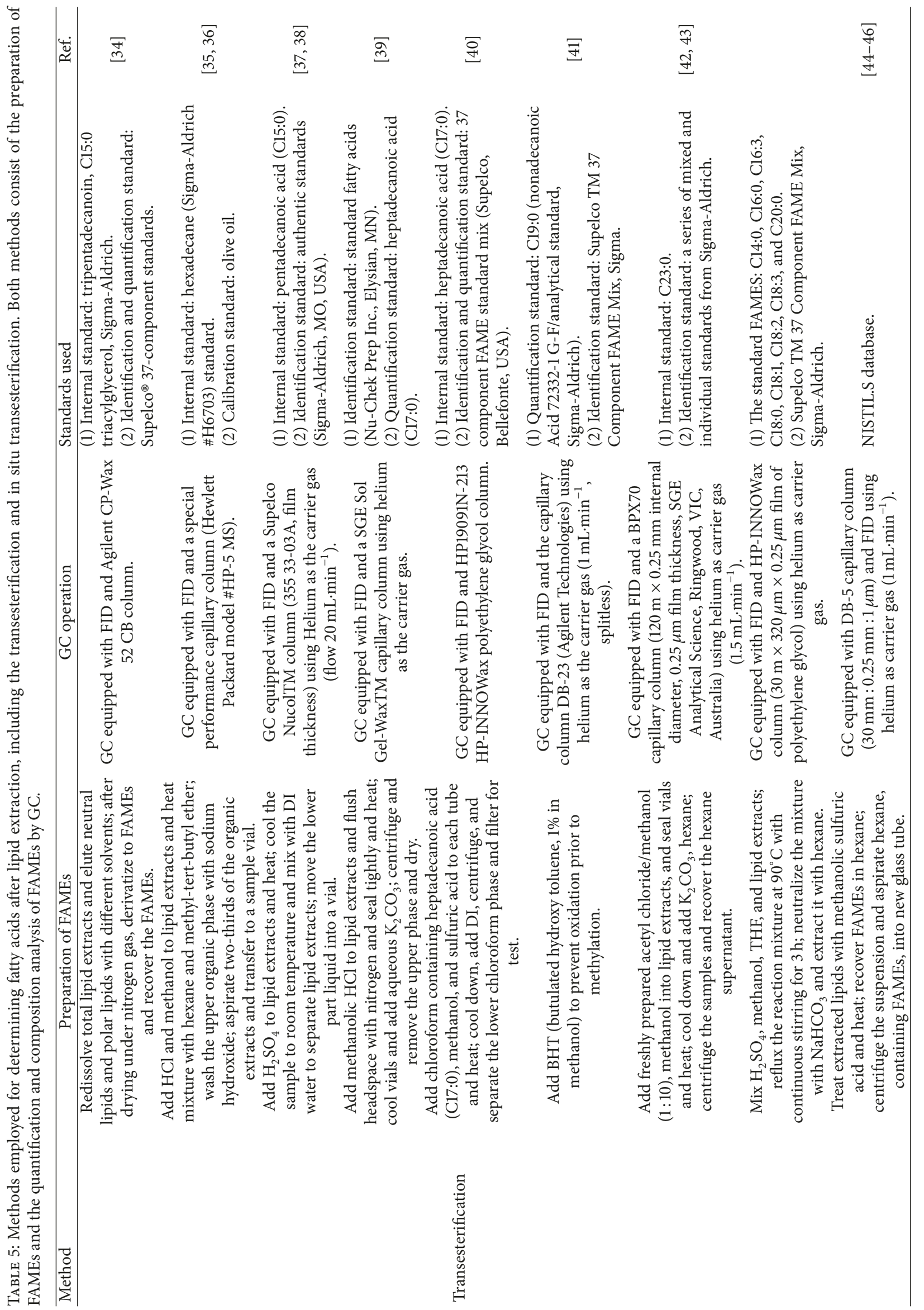




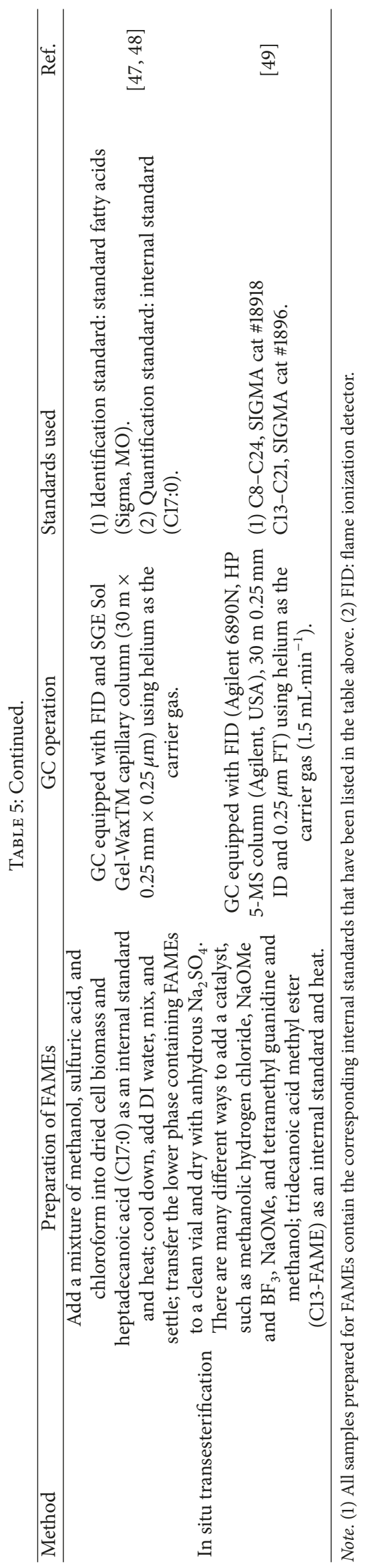




\section{Conflicts of Interest}

The authors declare that they have no conflicts of interest.

\section{Acknowledgments}

The authors would like to graciously acknowledge the National Natural Science Foundation of China (51708294), the Fundamental Research Funds for the Central Universities (30918011306 and 30918011308), and Research Start-Up Grant of NJUST for the funding and support provided for this research.

\section{References}

[1] S. Shafiee and E. Topal, "When will fossil fuel reserves be diminished?” Energy Policy, vol. 37, no. 1, pp. 181-189, 2009.

[2] Y. Chisti, "Biodiesel from microalgae," Biotechnology Advances, vol. 25, no. 3, pp. 294-306, 2007.

[3] A. Demirbas and M. F. Demirbas, "Importance of algae oil as a source of biodiesel," Energy Conversion and Management, vol. 52, no. 1, pp. 163-170, 2011.

[4] Y. Li, S. Lian, D. Tong et al., "One-step production of biodiesel from Nannochloropsis sp. on solid base Mg-Zr catalyst," Applied Energy, vol. 88, no. 10, pp. 3313-3317, 2011.

[5] I. Hariskos and C. Posten, "Biorefinery of microalgae - opportunities and constraints for different production scenarios," Biotechnology Journal, vol. 9, no. 6, pp. 739-752, 2014.

[6] M. R. Tredici, "Photobiology of microalgae mass cultures: Understanding the tools for the next green revolution," Biofuels, vol. 1, no. 1, pp. 143-162, 2010.

[7] S. Ge, P. Champagne, W. C. Plaxton, G. B. Leite, and F. Marazzi, "Microalgal cultivation with waste streams and metabolic constraints to triacylglycerides accumulation for biofuel production," Biofuels, Bioproducts and Biorefining, vol. 11, no. 2, pp. 325343, 2017.

[8] S. Ge and P. Champagne, "Nutrient removal, microalgal biomass growth, harvesting and lipid yield in response to centrate wastewater loadings," Water Research, vol. 88, pp. 604612, 2016.

[9] E. Sforza, R. Cipriani, T. Morosinotto, A. Bertucco, and G. M. Giacometti, "Excess CO 2 supply inhibits mixotrophic growth of Chlorella protothecoides and Nannochloropsis salina," Bioresource Technology, vol. 104, pp. 523-529, 2012.

[10] S. Ge, M. Agbakpe, Z. Wu, L. Kuang, W. Zhang, and X. Wang, "Influences of surface coating, UV irradiation and magnetic field on the algae removal using magnetite nanoparticles," Environmental Science \& Technology, vol. 49, no. 2, pp. 11901196, 2015.

[11] S. Ge, M. Agbakpe, W. Zhang, and L. Kuang, "Heteroaggregation between PEI-coated magnetic nanoparticles and algae: Effect of particle size on algal harvesting efficiency," ACS Applied Materials \& Interfaces, vol. 7, no. 11, pp. 6102-6108, 2015.

[12] S. Ge, P. Champagne, H. Wang, P. G. Jessop, and M. F. Cunningham, "Microalgae Recovery from Water for Biofuel Production Using CO2-Switchable Crystalline Nanocellulose," Environmental Science \& Technology, vol. 50, no. 14, pp. 78967903, 2016.

[13] A. Steriti, R. Rossi, A. Concas, and G. Cao, "A novel cell disruption technique to enhance lipid extraction from microalgae," Bioresource Technology, vol. 164, pp. 70-77, 2014.
[14] I. A. Guschina and J. L. Harwood, "Complex lipid biosynthesis and its manipulation in plants," Improvement of Crop Plants for Industrial End Uses, pp. 253-279, 2007.

[15] R. Halim, M. K. Danquah, and P. A. Webley, "Extraction of oil from microalgae for biodiesel production: a review," Biotechnology Advances, vol. 30, no. 3, pp. 709-732, 2012.

[16] M. A. Borowitzka and N. R. Moheimani, "Algae for biofuels and energy," Algae for Biofuels and Energy, pp. 1-288, 2013.

[17] T. M. Mata, A. A. Martins, and N. S. Caetano, "Microalgae for biodiesel production and other applications: a review," Renewable \& Sustainable Energy Reviews, vol. 14, no. 1, pp. 217$232,2010$.

[18] J. Kim, G. Yoo, H. Lee et al., "Methods of downstream processing for the production of biodiesel from microalgae," Biotechnology Advances, vol. 31, no. 6, pp. 862-876, 2013.

[19] R. Ranjith Kumar, P. Hanumantha Rao, and M. Arumugam, "Lipid Extraction Methods from Microalgae: A Comprehensive Review," Frontiers in Energy Research, vol. 2, 2015.

[20] A. K. Lee, D. M. Lewis, and P. J. Ashman, "Disruption of microalgal cells for the extraction of lipids for biofuels: Processes and specific energy requirements," Biomass \& Bioenergy, vol. 46, pp. 89-101, 2012.

[21] S. O. Kotchoni, E. W. Gachomo, K. Slobodenko, and D. H. Shain, "AMP deaminase suppression increases biomass, cold tolerance and oil content in green algae," Algal Research, vol. 16, pp. 473480, 2016.

[22] Y. Li, M. Horsman, B. Wang, N. Wu, and C. Q. Lan, "Effects of nitrogen sources on cell growth and lipid accumulation of green alga Neochloris oleoabundans," Applied Microbiology and Biotechnology, vol. 81, no. 4, pp. 629-636, 2008.

[23] W. Zhang, Y. Zhao, B. Cui, H. Wang, and T. Liu, "Evaluation of filamentous green algae as feedstocks for biofuel production," Bioresource Technology, vol. 220, pp. 407-413, 2016.

[24] A. Mehrabadi, M. M. Farid, and R. Craggs, "Effect of CO2 addition on biomass energy yield in wastewater treatment high rate algal mesocosms," Algal Research, vol. 22, pp. 93-103, 2017.

[25] Q. Lu, W. Zhou, M. Min et al., "Mitigating ammonia nitrogen deficiency in dairy wastewaters for algae cultivation," Bioresource Technology, vol. 201, pp. 33-40, 2016.

[26] A. Silkina, M.-P. Zacharof, G. Hery, T. Nouvel, and R. W. Lovitt, "Formulation and utilisation of spent anaerobic digestate fluids for the growth and product formation of single cell algal cultures in heterotrophic and autotrophic conditions," Bioresource Technology, vol. 244, pp. 1445-1455, 2017.

[27] B. T. Higgins, A. Thornton-Dunwoody, J. M. Labavitch, and J. S. Vandergheynst, "Microplate assay for quantitation of neutral lipids in extracts from microalgae," Analytical Biochemistry, vol. 465, pp. 81-89, 2014.

[28] A. E. M. Abdelaziz, G. B. Leite, M. A. Belhaj, and P. C. Hallenbeck, "Screening microalgae native to Quebec for wastewater treatment and biodiesel production," Bioresource Technology, vol. 157, pp. 140-148, 2014.

[29] Y.-Z. Wang, P. C. Hallenbeck, G. B. Leite, K. Paranjape, and D.Q. Huo, "Growth and lipid accumulation of indigenous algal strains under photoautotrophic and mixotrophic modes at low temperature," Algal Research, vol. 16, pp. 195-200, 2016.

[30] G. B. Leite, K. Paranjape, A. E. M. Abdelaziz, and P. C. Hallenbeck, "Utilization of biodiesel-derived glycerol or xylose for increased growth and lipid production by indigenous microalgae," Bioresource Technology, vol. 184, pp. 123-130, 2015. 
[31] J. C. Priscu, L. R. Priscu, A. C. Palmisano, and C. W. Sullivan, "Estimation of neutral lipid levels in antarctic sea ice microalgae by nile red fluorescence," Antarctic Science, vol. 2, no. 2, pp. 149155, 1986.

[32] T. White, S. Bursten, D. Federighi, R. A. Lewis, and E. Nudelman, "High-resolution separation and quantification of neutral lipid and phospholipid species in mammalian cells and sera by multi-one-dimensional thin-layer chromatography," Analytical Biochemistry, vol. 258, no. 1, pp. 109-117, 1998.

[33] J. Liu, J. Huang, Z. Sun, Y. Zhong, Y. Jiang, and F. Chen, "Differential lipid and fatty acid profiles of photoautotrophic and heterotrophic Chlorella zofingiensis: Assessment of algal oils for biodiesel production," Bioresource Technology, vol. 102, no. 1, pp. 106-110, 2011.

[34] C. J. Hulatt, O. Berecz, E. S. Egeland, R. H. Wijffels, and V. Kiron, "Polar snow algae as a valuable source of lipids?" Bioresource Technology, vol. 235, pp. 338-347, 2017.

[35] S. N. Genin, J. Stewart Aitchison, and D. Grant Allen, "Design of algal film photobioreactors: Material surface energy effects on algal film productivity, colonization and lipid content," Bioresource Technology, vol. 155, pp. 136-143, 2014.

[36] I. Smid and M. Salfinger, "Mycobacterial identification by computer-aided gas-liquid chromatography," Diagnostic Microbiology And Infectious Disease, vol. 19, no. 2, pp. 81-88, 1994.

[37] H.-M. Pham, H. S. Kwak, M.-E. Hong, J. Lee, W. S. Chang, and S. J. Sim, "Development of an X-Shape airlift photobioreactor for increasing algal biomass and biodiesel production," Bioresource Technology, vol. 239, pp. 211-218, 2017.

[38] A. M. Santos, M. Janssen, P. P. Lamers, W. A. C. Evers, and R. H. Wijffels, "Growth of oil accumulating microalga Neochloris oleoabundans under alkaline-saline conditions," Bioresource Technology, vol. 104, pp. 593-599, 2012.

[39] D. J. Pyle, R. A. Garcia, and Z. Wen, "Producing docosahexaenoic acid (DHA)-rich algae from biodiesel-derived crude glycerol: Effects of impurities on DHA production and algal biomass composition," Journal of Agricultural and Food Chemistry, vol. 56, no. 11, pp. 3933-3939, 2008.

[40] S. K. Mishra, W. I. Suh, W. Farooq et al., "Rapid quantification of microalgal lipids in aqueous medium by a simple colorimetric method," Bioresource Technology, vol. 155, pp. 330-333, 2014.

[41] M. Tossavainen, A. Nykänen, K. Valkonen, A. Ojala, S. Kostia, and M. Romantschuk, "Culturing of Selenastrum on diluted composting fluids; conversion of waste to valuable algal biomass in presence of bacteria," Bioresource Technology, vol. 238, pp. 205-213, 2017.

[42] N. D. Q. Duy, D. S. Francis, and P. C. Southgate, “The nutritional value of live and concentrated micro-algae for early juveniles of sandfish, Holothuria scabra," Aquaculture, vol. 473, pp. 97-104, 2017.

[43] J. A. Conlan, P. L. Jones, G. M. Turchini, M. R. Hall, and D. S. Francis, "Changes in the nutritional composition of captive early-mid stage Panulirus ornatus phyllosoma over ecdysis and larval development," Aquaculture, vol. 434, pp. 159-170, 2014.

[44] N. Arora, A. Patel, P. A. Pruthi, and V. Pruthi, "Recycled deOiled algal biomass extract as a feedstock for boosting biodiesel production from chlorella minutissima," Applied Biochemistry and Biotechnology, vol. 180, no. 8, pp. 1534-1541, 2016.

[45] N. Arora, A. Patel, P. A. Pruthi, and V. Pruthi, "Synergistic dynamics of nitrogen and phosphorous influences lipid productivity in Chlorella minutissima for biodiesel production," Bioresource Technology, vol. 213, pp. 79-87, 2015.
[46] P. Jain, N. Arora, J. Mehtani, V. Pruthi, and C. B. Majumder, "Pretreated algal bloom as a substantial nutrient source for microalgae cultivation for biodiesel production," Bioresource Technology, vol. 242, pp. 152-160, 2017.

[47] Z. Chi, D. Pyle, Z. Wen, C. Frear, and S. Chen, "A laboratory study of producing docosahexaenoic acid from biodiesel-waste glycerol by microalgal fermentation," Process Biochemistry, vol. 42, no. 11, pp. 1537-1545, 2007.

[48] E. Indarti, M. I. A. Majid, R. Hashim, and A. Chong, "Direct FAME synthesis for rapid total lipid analysis from fish oil and cod liver oil," Journal of Food Composition and Analysis, vol. 18, no. 2-3, pp. 161-170, 2005.

[49] L. M. L. Laurens, M. Quinn, S. Van Wychen, D. W. Templeton, and E. J. Wolfrum, "Accurate and reliable quantification of total microalgal fuel potential as fatty acid methyl esters by in situ transesterification," Analytical and Bioanalytical Chemistry, vol. 403, no. 1, pp. 167-178, 2012.

[50] S. Balasubramanian, J. D. Allen, A. Kanitkar, and D. Boldor, "Oil extraction from Scenedesmus obliquus using a continuous microwave system - design, optimization, and quality characterization," Bioresource Technology, vol. 102, no. 3, pp. 3396-3403, 2011.

[51] F. Amarni and H. Kadi, "Kinetics study of microwave-assisted solvent extraction of oil from olive cake using hexane. Comparison with the conventional extraction," Innovative Food Science and Emerging Technologies, vol. 11, no. 2, pp. 322-327, 2010.

[52] A. F. Ferreira, A. P. S. Dias, C. M. Silva, and M. Costa, "Effect of low frequency ultrasound on microalgae solvent extraction: Analysis of products, energy consumption and emissions," Algal Research, vol. 14, pp. 9-16, 2016.

[53] K. S. Suslick and D. J. Flannigan, "Inside a collapsing bubble: Sonoluminescence and the conditions during cavitation," Annual Review of Physical Chemistry, vol. 59, pp. 659-683, 2008.

[54] F. Adam, M. Abert-Vian, G. Peltier, and F. Chemat, “'Solventfree' ultrasound-assisted extraction of lipids from fresh microalgae cells: a green, clean and scalable process," Bioresource Technology, vol. 114, pp. 457-465, 2012.

[55] M. S. Doulah, "Mechanism of disintegration of biological cells in ultrasonic cavitation," Biotechnology and Bioengineering, vol. 19, no. 5, pp. 649-660, 1977.

[56] R. Halim, A. Hosikian, S. Lim, and M. K. Danquah, "Chlorophyll extraction from microalgae: A review on the process engineering aspects," International Journal of Chemical Engineering, Article ID 391632, 2010.

[57] M. Vaara, "Agents that increase the permeability of the outer membrane," Microbiology and Molecular Biology Reviews, vol. 56, no. 3, pp. 395-411, 1992.

[58] A. Sathish and R. C. Sims, "Biodiesel from mixed culture algae via a wet lipid extraction procedure," Bioresource Technology, vol. 118, pp. 643-647, 2012.

[59] M. Demuez, A. Mahdy, E. Tomás-Pejó, C. González-Fernández, and M. Ballesteros, "Enzymatic cell disruption of microalgae biomass in biorefinery processes," Biotechnology and Bioengineering, vol. 112, no. 10, pp. 1955-1966, 2015.

[60] A. Zuorro, G. Maffei, and R. Lavecchia, "Optimization of enzyme-assisted lipid extraction from Nannochloropsis microalgae," Journal of the Taiwan Institute of Chemical Engineers, vol. 67, pp. 106-114, 2016.

[61] K. Kita, S. Okada, H. Sekino, K. Imou, S. Yokoyama, and T. Amano, "Thermal pre-treatment of wet microalgae harvest for efficient hydrocarbon recovery," Applied Energy, vol. 87, no. 7, pp. 2420-2423, 2010. 
[62] Y.-S. Cheng, Y. Zheng, and J. S. VanderGheynst, "Rapid quantitative analysis of lipids using a colorimetric method in a microplate format," Lipids, vol. 46, no. 1, pp. 95-103, 2011.

[63] W. Chen, C. Zhang, L. Song, M. Sommerfeld, and Q. Hu, “A high throughput Nile red method for quantitative measurement of neutral lipids in microalgae," Journal of Microbiological Methods, vol. 77, no. 1, pp. 41-47, 2009.

[64] I. R. Sitepu, L. Ignatia, A. K. Franz et al., "An improved high-throughput Nile red fluorescence assay for estimating intracellular lipids in a variety of yeast species," Journal of Microbiological Methods, vol. 91, no. 2, pp. 321-328, 2012.

[65] Y. Tang, Y. Zhang, J. N. Rosenberg, N. Sharif, M. J. Betenbaugh, and F. Wang, "Efficient lipid extraction and quantification of fatty acids from algal biomass using accelerated solvent extraction (ASE)," RSC Advances, vol. 6, no. 35, pp. 29127-29134, 2016.

[66] L. Lardon, A. Helias, B. Sialve, J. P. Steyer, and O. Bernard, "Lifecycle assessment of biodiesel production from microalgae," Environmental Science \& Technology, vol. 43, no. 17, pp. 64756481, 2009.

[67] P. Mercer and R. E. Armenta, "Developments in oil extraction from microalgae," European Journal of Lipid Science and Technology, vol. 113, no. 5, pp. 539-547, 2011.

[68] R. L. Mendes, A. D. Reis, and A. F. Palavra, "Supercritical $\mathrm{CO}_{2}$ extraction of $\gamma$-linolenic acid and other lipids from Arthrospira (Spirulina)maxima: comparison with organic solvent extraction," Food Chemistry, vol. 99, no. 1, pp. 57-63, 2006.

[69] G. Andrich, U. Nesti, F. Venturi, A. Zinnai, and R. Fiorentini, "Supercritical fluid extraction of bioactive lipids from the microalga Nannochloropsis sp.", European Journal of Lipid Science and Technology, vol. 107, no. 6, pp. 381-386, 2005.

[70] C. Crampon, A. Mouahid, S.-A. A. Toudji, O. Lépine, and E. Badens, "Influence of pretreatment on supercritical CO2 extraction from Nannochloropsis oculata," The Journal of Supercritical Fluids, vol. 79, pp. 337-344, 2013.

[71] A. Mouahid, C. Crampon, S.-A. A. Toudji, and E. Badens, "Supercritical CO2 extraction of neutral lipids from microalgae: Experiments and modelling," The Journal of Supercritical Fluids, vol. 77, pp. 7-16, 2013.

[72] R. Halim, B. Gladman, M. K. Danquah, and P. A. Webley, "Oil extraction from microalgae for biodiesel production," Bioresource Technology, vol. 102, no. 1, pp. 178-185, 2011.

[73] L. Soh and J. Zimmerman, "Biodiesel production: The potential of algal lipids extracted with supercritical carbon dioxide," Green Chemistry, vol. 13, no. 6, pp. 1422-1429, 2011.

[74] B.-C. Liau, C.-T. Shen, F.-P. Liang et al., "Supercritical fluids extraction and anti-solvent purification of carotenoids from microalgae and associated bioactivity," The Journal of Supercritical Fluids, vol. 55, no. 1, pp. 169-175, 2010.

[75] A. Paudel, M. J. Jessop, S. H. Stubbins, P. Champagne, and P. G. Jessop, "Extraction of lipids from microalgae using CO2expanded methanol and liquid CO2," Bioresource Technology, vol. 184, pp. 286-290, 2015.

[76] B. Subramaniam, R. V. Chaudhari, A. S. Chaudhari, G. R. Akien, and Z. Xie, "Supercritical fluids and gas-expanded liquids as tunable media for multiphase catalytic reactions," Chemical Engineering Science, vol. 115, pp. 3-18, 2014.

[77] P. G. Jessop and B. Subramaniam, "Gas-expanded liquids," Chemical Reviews, vol. 107, no. 6, pp. 2666-2694, 2007.
[78] H.-C. Wang, W. Klinthong, Y.-H. Yang, and C.-S. Tan, "Continuous extraction of lipids from Schizochytrium sp. by CO2expanded ethanol," Bioresource Technology, vol. 189, pp. 162-168, 2015.

[79] B. Subramaniam and G. R. Akien, "Sustainable catalytic reaction engineering with gas-expanded liquids," Current Opinion in Chemical Engineering, vol. 1, no. 3, pp. 336-341, 2012.

[80] Y.-H. Yang, W. Klinthong, and C.-S. Tan, "Optimization of continuous lipid extraction from Chlorella vulgaris by CO2expanded methanol for biodiesel production," Bioresource Technology, vol. 198, pp. 550-556, 2015.

[81] S. Wahidin, A. Idris, and S. R. M. Shaleh, "Ionic liquid as a promising biobased green solvent in combination with microwave irradiation for direct biodiesel production," Bioresource Technology, vol. 206, pp. 150-154, 2016.

[82] Y. Chisti, "Biodiesel from microalgae beats bioethanol," Trends in Biotechnology, vol. 26, no. 3, pp. 126-131, 2008.

[83] R. E. Teixeira, "Energy-efficient extraction of fuel and chemical feedstocks from algae," Green Chemistry, vol. 14, no. 2, pp. 419427, 2012.

[84] K. Gao, V. Orr, and L. Rehmann, "Butanol fermentation from microalgae-derived carbohydrates after ionic liquid extraction," Bioresource Technology, vol. 206, pp. 77-85, 2016.

[85] P. G. Jessop, D. J. Heldebrant, X. Li, C. A. Eckertt, and C. L. Liotta, "Green chemistry: Reversible nonpolar-to-polar solvent," Nature, vol. 436, no. 7054, p. 1102, 2005.

[86] P. G. Jessop, "Switchable solvents as media for synthesis and separations: An update from the co-creator of GreenCentre Canada," Aldrichimica Acta, vol. 48, no. 1, pp. 18-21, 2015.

[87] V. C. A. Orr and L. Rehmann, "Ionic liquids for the fractionation of microalgae biomass," Current Opinion in Green and Sustainable Chemistry, vol. 2, pp. 22-27, 2016.

[88] P. G. Jessop, L. Phan, A. Carrier, S. Robinson, C. J. Dürr, and J. R. Harjani, "A solvent having switchable hydrophilicity," Green Chemistry, vol. 12, no. 5, pp. 809-814, 2010.

[89] P. G. Jessop, L. Kozycz, Z. G. Rahami et al., "Tertiary amine solvents having switchable hydrophilicity;" Green Chemistry, vol. 13, no. 3, pp. 619-623, 2011.

[90] G. H. Huang, G. Chen, and F. Chen, "Rapid screening method for lipid production in alga based on Nile red fluorescence," Biomass \& Bioenergy, vol. 33, no. 10, pp. 1386-1392, 2009.

[91] L. S. Inouye and G. R. Lotufo, "Comparison of macrogravimetric and micro-colorimetric lipid determination methods," Talanta, vol. 70, no. 3, pp. 584-587, 2006.

[92] B. Fuchs, R. Süß, K. Teuber, M. Eibisch, and J. Schiller, "Lipid analysis by thin-layer chromatography-a review of the current state," Journal of Chromatography A, vol. 1218, no. 19, pp. 27542774, 2011.

[93] P. Pesaresi, J. S. Amthor, G. Mandolino, and etal., Improvement of Crop Plants for Industrial End Uses, Springer, Netherlands, 2007.

[94] H. Liu and W. Liu, "Concentration and distributions of fatty acids in algae, submerged plants and terrestrial plants from the northeastern Tibetan Plateau," Organic Geochemistry, vol. 113, pp. 17-26, 2017.

[95] V. Kumar, M. Muthuraj, B. Palabhanvi, A. K. Ghoshal, and D. Das, "Evaluation and optimization of two stage sequential in situ transesterification process for fatty acid methyl ester quantification from microalgae," Journal of Renewable Energy, vol. 68 , pp. 560-569, 2014. 
[96] S. Van Wychen, K. Ramirez, and L. M. Laurens, Determination of Total Lipids as Fatty Acid Methyl Esters (FAME) by In Situ Transesterification, Laboratory Analytical Procedure (LAP), National Renewable Energy Laboratory (NREL), Golden, Colo, USA, 2013.

[97] G. Knothe, "Improving biodiesel fuel properties by modifying fatty ester composition," Energy \& Environmental Science, vol. 2, no. 7, pp. 759-766, 2009. 


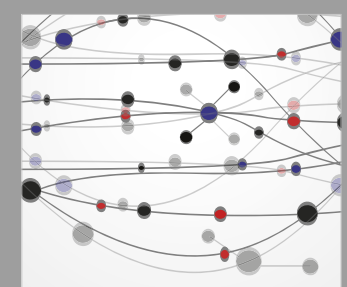

The Scientific World Journal
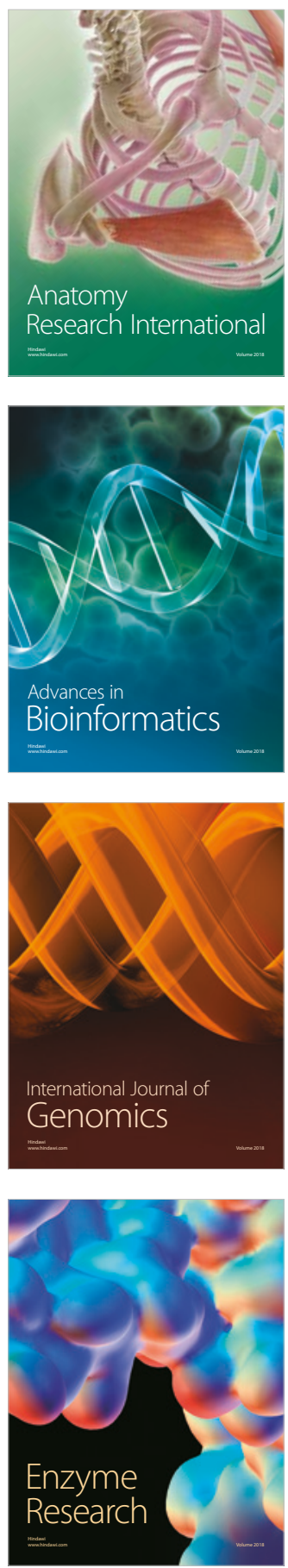
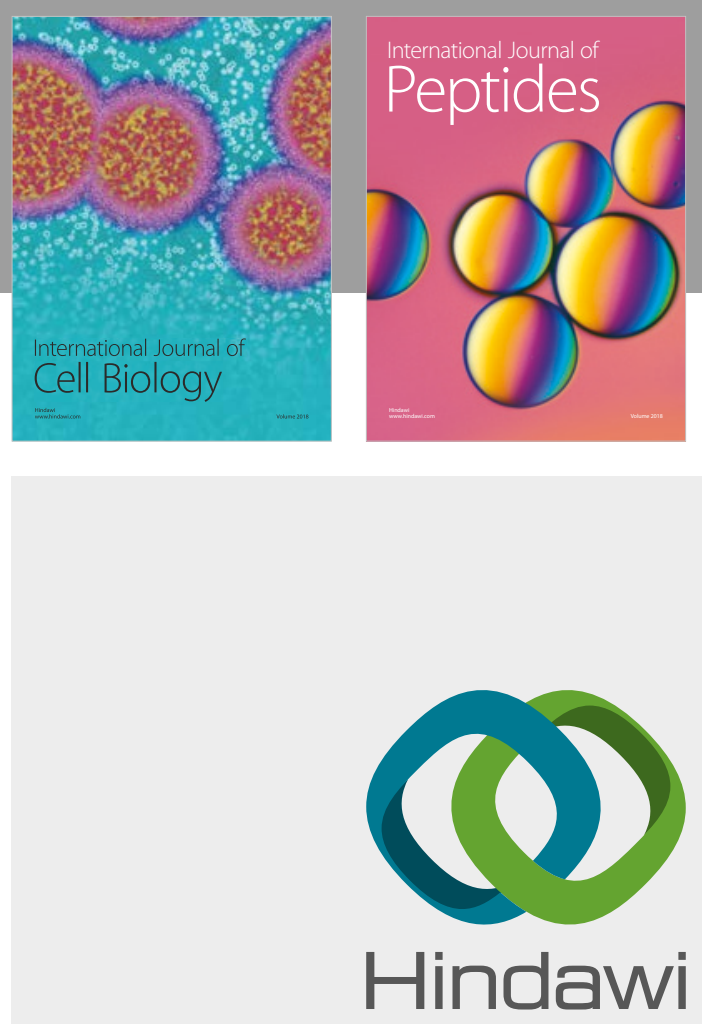

Submit your manuscripts at

www.hindawi.com
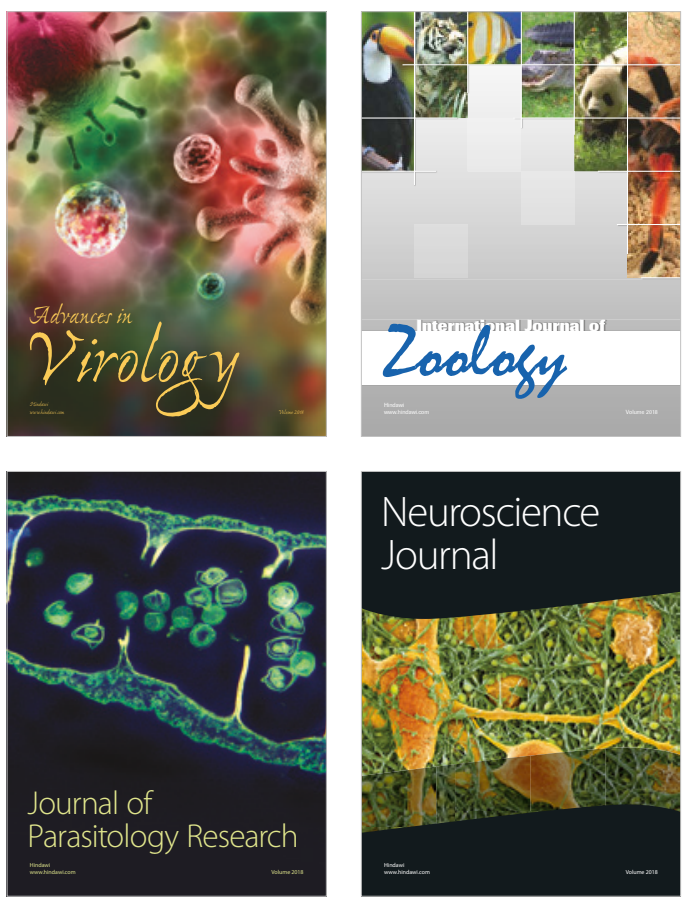
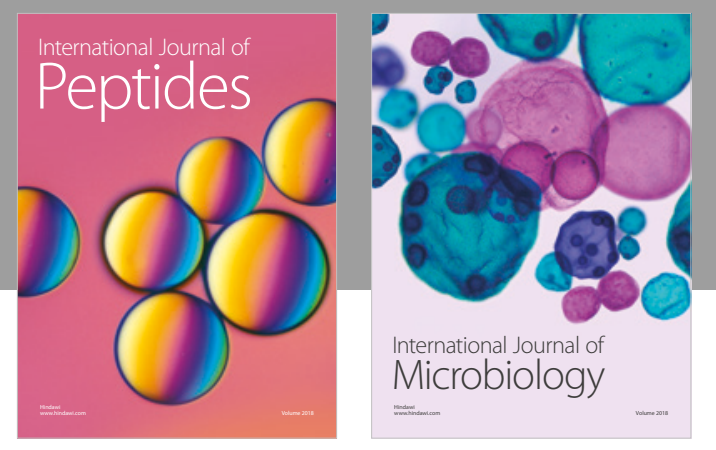

nternational Journal of Microbiology
Journal of
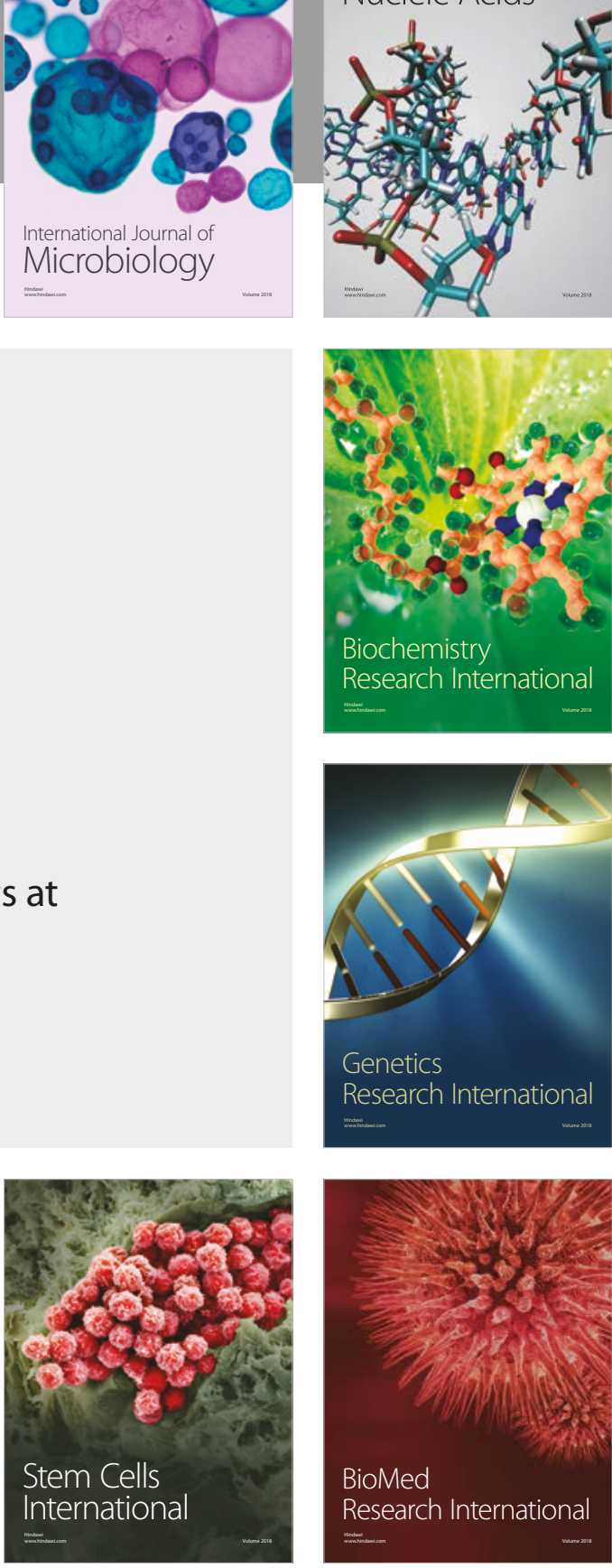
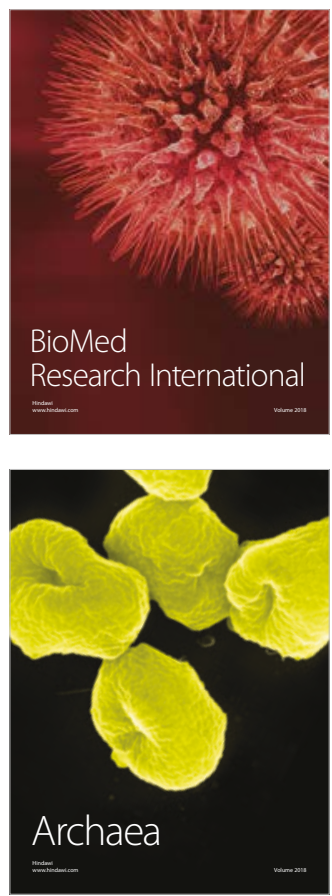